\title{
La élite política de Huelva ante la contienda electoral de 1923
}

\author{
María Antonia Peña Guerrero*
}

\section{INTRODUCCIÓN}

Emprender el estudio de la élite política de Huelva y su comportamiento durante el período electoral de 1923 presenta para nosotros un doble interés. Por un lado, y en la medida en que la historia contemporánea onubense sigue siendo una gran desconocida, es nuestro objetivo contribuir a la colmatación de una extensa laguna historiográfica que requiere, con urgencia, una mayor atención de la que hasta ahora se le ha prestado. Por otro lado, y en un sentido más amplio, pretendemos proceder al análisis -en el marco de una sociedad de provincias de tipo medio- de una encrucijada histórica donde aparecen implicados fenómenos tan significativos como la crisis del sistema canovista, los planteamientos reformadores de la Concentración Liberal y el propio advenimiento de la Dictadura de Primo de Rivera.

A pesar de haber sido abordados en numerosas ocasiones, estos tres temas, que determinan de algún modo el verdadero sentido de la convocatoria electoral de 1923, siguen sugiriéndonos hoy día interrogantes de gran importancia que permanecen sin una respuesta convincente. Si bien parece un hecho incuestionable la caducidad del sistema político canovista en 1923, queda aún pendiente un planteamiento crítico sobre

\footnotetext{
* Universidad de Sevilla.
} 
cuáles fueron las realizaciones efectivas del Gobierno garciprietista ${ }^{\dagger}$ y qué relación existió entre éstas y el pronunciamiento militar del 13 de septiembre. ¿Demostraba éste la incapacidad del sistema para depurar sus propias lacras y llevar a cabo la incorporación de las masas a la vida política? ¿Significaba, por el contrario, una reacción de determinados grupos de poder a la democratización y regeneración interna del régimen? ¿Hasta qué punto fueron factibles las propuestas reformistas gubernamentales? ¿Se trataba sólo de planteamientos de gabinete o hubo un intento responsable de ejecutarlas? Sin que, por el momento, podamos más que apuntar las bases sobre las que ha de reconstruirse este momento clave en nuestra historia nacional más reciente, parece evidente, al menos, que responder a estas cuestiones impone un análisis más profundo y pormenorizado del contenido ideológico de la Concentración Liberal, sus proyectos, la factibilidad de éstos y su desarrollo concreto en los meses de Gobierno que mediaron entre diciembre de 1922 y septiembre de 1923 .

Entre otros puntos de referencia para iniciar esta tarea, contamos con un acontecimiento relevante: las elecciones de 1923, que -encargadas de ratificar oficialmente el desempeño del poder por parte de la agrupación liberal- capitalizaron, durante varios meses, el interés de la opinión pública por el funcionamiento de la maquinaria política de la Restauración. Aunque González Calbet ha señalado recientemente la importancia de esta convocatoria electoral para comprobar la veracidad de los intentos democratizadores del Gobierno ${ }^{2}$, el papel de este evento en el contexto de las reformas gubernamentales sigue siendo un espacio historiográfico prácticamente vacío. Rutinarias como el propio turno de partidos, pero encajadas en una coyuntura crítica, debemos cuestionarnos si realmente las elecciones se llevaron a cabo como siempre o si, por el contrario, reflejaron el clima de regeneración emanado por la cúpula del poder; si indujeron a las élites políticas a un replanteamiento de las estructuras políticas vigentes o si, en cambio, perpetuaron los mecanismos electorales caciquiles en los que aquéllas estaban mayoritariamente entrenadas. $Y$, finalmente, si -a través de los registros de la prensa-

1 Sobre la interpretación del programa reformista de la Concentración Liberal, vid. SECo Serrano, C., Alfonso XIII y la crisis de la Restauración. Barcelona, Ariel, 1969; Carr, Raymond, España, 1808-1939. Barcelona, Ariel, 1969; TuselL, J. y GARCíA, G., “La Dictadura de Primo de Rivera como régimen político. Un intento de interpretación", Cuadernos Económicos de ICE, 10, (1979); BeN-AMI, Shlomo, La Dictadura de Primo de Rivera, 19231930. Barcelona, Planeta, 1984; González Calbet, María Teresa, La Dictadura de Primo de Rivera. El Directorio Militar. Madrid, El Arquero, 1987.

${ }^{2}$ González Calbet, M. T., Op. cit., pág. 105. 
podemos ver algún cambio de posición en la opinión pública, abandonando ésta su habitual desconfianza y depositando sus esperanzas en los nuevos comicios.

Para intentar dar respuesta a tan amplias cuestiones hemos limitado nuestro campo de acción a un caso concreto: el comportamiento de la élite política de Huelva ante la contienda electoral de $1923^{3}$.

\section{EL MOMENTO POLÍTICO ONUBENSE}

\subsection{La situación de los partidos}

Para cualquiera que se detuviese a observar el panorama político onubense a la altura de 1923, la situación no podía ser más desesperanzadora. La sensación de vacío político y de crisis interna debía ser, desde luego, la predominante, especialmente en aquéllos que hubiesen conocido las pasadas glorias del turnismo o los mejores momentos de las fuerzas antidinásticas. La llegada al poder de la Concentración Liberal en diciembre de 1922 encontró, de hecho, en la provincia de Huelva una estructura de poder inveterada, consolidada por largos períodos de caciquismo e influencias personales, pero en gran parte vacía de contenido, incapaz ya de arrastrar la más mínima de las voluntades o de ofrecer una nueva propuesta de futuro en la que confiar. Así pues, continuaban el prestigio, las adulaciones y el dominio, pero ahora se les añadían las críticas, la desconfianza y el descrédito. Ante todo, el vacio interior.

Aún afectado por este clima general, el partido conservador seguía siendo en Huelva la primera e indiscutible fuerza política de la provincia. Dos razones fundamentales explican esta posición de privilegio mantenida a lo largo de los años. Así las exponía el escritor Balbino Aguirre Lazareno en 1919:

«... el partido conservador, desde que está dirigido por don Manuel de Burgos, es en Huelva el único, realmente, que como partido político

${ }^{3}$ Por razones de espacio, hemos tenido que centramos básicamente en las elecciones de diputados del mes de abril, tratando sólo marginalmente las del Senado y Diputación Provincial. 
con vida propia existe; pues los demás, que sólo tienen de partidos la cualidad de estarlo en muchos pedazos, obedeciendo la ley universal de inercia, giran alrededor de él con grande y fatal velocidad" 4 .

Estas palabras - perfectamente aplicables cuatro años despuéstraducian con gran transparencia la situación política onubense, determinada básicamente por la desintegración del grupo liberal y la gran influencia ejercida por el cacicato del ex-ministro conservador. Es más, si cabe, estas dos condiciones aparecían reforzadas en 1923. La escisión definitiva de los liberales, separados en romanonistas o "limonistas" - seguidores de su jefe provincial, José Limón Caballero-y albistas - acaudillados por Guillermo Moreno Calvo-, beneficiaba indirectamente el predominio de los conservadores. Por otro lado, en el mare magnum de las críticas a la vieja política y candente como estaba, desde 1921, el espinoso tema de las "responsabilidades", las duras manifestaciones de Burgos y Mazo contra las negligencias gubernamentales habian revalidado, en cierto modo, su prestigio entre la oligarquía política onubense, que no dejaba de reconocerlo como «uno de los políticos menos políticos de nuestra patria» ${ }^{5}$. Y esto, lógicamente, en 1923, era todo un halago.

A no ser grupos “radicales" -como, por ejemplo, los republicanos-, ninguna formación política osaba en Huelva alzar su voz contra el viejo jefe conservador. Por el contrario, cualquier ocasión era aprovechada para rendirle honores y ofrecerle demostraciones de devoción desde todos los frentes. Si esto era así incluso entre los supuestamente enemigos políticos, poco podemos añadir respecto a la cohesión interna del grupo conservador. Bajo «el benéfico influjo de su nuevo líder», comentaría Aguirre Lazareno, el partido se había constituido como "un ejército político tan admirablemente disciplinado que, a una voz de su caudillo, movíase con automática regularidad" ${ }^{\circ}$. Y, en efecto, así era. Ninguna decisión parecía tomarse sin contar antes con el beneplácito de Burgos y Mazo, de tal manera que, aun después de ceder la jefatura provincial a Francisco Javier Sánchez Dalp, marqués de Aracena, el exministro siguió manteniendo una constante tutela sobre la política onubense. Hacia 1923, por lo demás, no aparece noticia alguna sobre la fracción maurista del partido. Ésta, que habia sido duramente atacada

\footnotetext{
${ }^{4}$ Aguirre Lazareno, Balbino, Siluetas de hombres ilustres de Huelva y su provincia. Huelva, 1919, pág. 49.

${ }^{5}$ La Provincia, 5-4-1923.

${ }^{6}$ Aguirre Lazareno, B., Op. cit., págs. 48 y s.
} 
por Burgos y Mazo durante las elecciones de 1919, no da señales de vida. Aunque algunos de sus hombres más destacados -Quintero Báez y Carlos y Fernando Rey Schuler, entre ellos - formarán parte, posteriormente, de los cuadros políticos de la Dictadura, meses antes del advenimiento de ésta nada se sabía del funcionamiento del partido maurista. De hecho, Manuel Fernández Balbuena, destacado maurista, se presentará como candidato en la contienda de 1923 en calidad de independiente ${ }^{7}$.

Libre así de enemistades externas, podría pensarse a primera vista que los conservadores de Huelva atravesaban una buena coyuntura en este momento.

No obstante, ya lo dijimos, ocurría todo lo contrario. Aparte la repercusión que sobre la organización provincial pudiese tener la crisis del partido a escala nacional, otros problemas vinieron a ensombrecer su horizonte político. Por un lado, la vacante de la jefatura local de Huelva desde la muerte, en noviembre de 1922, del alcalde Antonio de Mora Claros, un hombre poderoso, de extremada influencia en los círculos políticos onubenses y, por ello, muy difícil de sustituir. Por otro lado, las diferencias existentes entre el marqués de Aracena y Burgos y Mazo debido a las excesivas injerencias de éste en las competencias del primero. Durante la elaboración del encasillado -como tendremos ocasión de comprobar-, estas diferencias se acentuarán hasta el punto de provocar un verdadero enfriamiento de las relaciones entre ambos líderes. En los meses anteriores a la contienda electoral, el partido perdió, además, algunos de sus miembros más relevantes. El fallecimiento de Espina Soldán y García Ramos y la retirada de la política activa del senador Manuel Rebollo Orta marcaban, en este sentido, la imperiosa necesidad de llevar a cabo una renovación de las filas conservadoras. Sin embargo, la savia joven que parecía estar destinada a este in no presentaba, en absoluto, el mismo carisma y las cualidades de sus antecesores. Este era el caso concreto de Manuel de Burgos Domínguez, hijo de Burgos y Mazo y candidato a Cortes en 1923, que no estaba, ni mucho menos, a la altura de su progenitor.

Este agotamiento del sector conservador fue probablemente advertido por el resto de las fuerzas políticas que, aun siendo incapaces de

${ }^{7}$ Sobre la crisis del maurismo onubense en 1919 proporciona abundante información la prensa onubense y sevillana de mayo y junio de este año. Como resultado del conflicto el comité maurista estuvo a punto de disolverse y muchos de sus componentes más relevantes abandonaron sus filas. 
ofrecer una verdadera alternativa de poder, venían emprendiendo en los últimos tiempos una auténtica ofensiva contra sus posiciones hegemónicas. Poco antes de morir, el mismo Mora Claros hubo de afrontar una moción de censura por parte de los concejales de la oposición, que lo acusaban de parcialidad en las discusiones capitulares y favoritismo hacia los ediles de su grupo ${ }^{8}$. Su sucesor como presidente accidental de la Corporación, José de la Corte Gutiérrez, hubo igualmente de sufrir numerosas acusaciones contra la gestión administrativa de los conservadores. Las minorías liberales y republicana atacaron duramente la elaboración de los presupuestos en marzo del veintitres, considerándolo abiertamente un "saqueo del Erario municipal" " y desataron un verdadero escándalo popular en torno al cobro de arbitrios ilegales a los comerciantes. Este último asunto manchó considerablemente la reputación conservadora en lo referente a su actuación pública, especialmente cuando las protestas llegaron incluso a provocar manifestaciones y una huelga de veinticuatro horas seguida masivamente por los establecimientos comerciales. Finalmente se hizo imprescindible la mediación del gobernador civil; los problemas se solucionaron, pero el descrédito del Ayuntamiento conservador era ya indeleble ${ }^{10}$.

En este ambiente de tensiones capitulares, podía percibirse claramente una corriente de agresividad creciente proyectada contra el antes intocable partido conservador. Las críticas al uso indebido de influencias y manejos caciquiles abandonaban así su limitación a las páginas periodísticas más independientes y entraban con toda facilidad en el discurso de las discusiones municipales. En este orden de cosas, y tras el intento de José de la Corte de nombrar a José Tercero médico municipal, los representantes de las minorías se apresuraron a denunciar que el nombramiento se debía a "presiones políticas" ejercidas sobre "el gobernador y los caciques» ${ }^{11}$. Empañada hasta este punto la reputación de los conservadores - paladines siempre de la moralidad-, las oposiciones más radicales sólo tenían que acabar de sembrar el recelo en la opinión popular. En esta línea, la campaña más activa fue realizada por los republicanos -enemigos acérrimos y personales de Burgos y Mazo-, que aprovecharon el banquete ofrecido en su honor el cinco de abril para distribuir unas hojas donde irónicamente se encomiaba la «fructífera y

${ }^{8}$ Archivo Municipal de Huelva (AMH), Acta Capitular del 22-9-1922, leg. 58.

${ }^{9}$ La Provincia, 7 y 8-3-1923.

${ }^{10}$ El desarrollo del conflicto puede seguirse en La Provincia y El Liberal (Sevilla) de abril de 1923.

${ }^{14}$ La Provincia, 24-3-1923 y AMH, Acta Capitular del 23-3-1923, leg. 58. 
redentora labor» que el señor de Moguer había realizado en la provincia $^{12}$.

Ahora bien, es obvio que desgastar la imagen pública de los conservadores sólo podía contribuir a generar un vacío político que ninguna otra fuerza estaba en condiciones de ocupar. A diferencia de otros lugares, como Sevilla, no existían aquí grupos pujantes del tipo de la Liga Católica, el maurismo o la Unión Comercial que pudiesen acoger las disidencias ganando terreno a la derecha canovista. Era imposible, así pues, que se llevase a cabo una "transmisión de poderes" entre las distintas fuerzas onubenses ${ }^{13}$. En su lugar, lo que podemos constatar es una situación de expectación e impasse político: avidez de cambios, pero también indeterminación. Este era el estado de la política provincial que recibió a la Dictadura de Primo de Rivera. Ni los republicanos -carentes de una cabeza directora fuerte desde la muerte de Manuel María de Soto Vázquez en 1917- ni los liberales -afanados en sus propias divergencias- podian sacar la política onubense de su atonía. Quedaba, eso sí, una tercera alternativa: el partido reformista. Acaudillados por José Marchena Colombo, un ex-republicano de gran prestigio en los ambientes culturales de la provincia, los reformistas onubenses parecían, con vistas a la contienda electoral de 1923, una fuerza con futuro. En más de una ocasión la prensa independiente se había manifestado en este sentido, augurando un gran horizonte político al reformismo de la provincia. Sin embargo, en un sentido estricto, hemos de reconocer que el partido reformista onubense era poco más que la figura de su presidente. Decir reformismo sólo era decir Marchena. De hecho, en 1923, el partido no contaba con bases lo suficientemente consolidadas y dilatadas como para pensar plantearse un asalto al poder.

En este panorama, donde reinaba la indefinición y el desconcierto, la animación política de los meses que precedieron a los comicios de abril vino del brazo de tres hechos principales: los cambios introducidos en la provincia por la Concentración Liberal, los proyectos de reforma del Gobierno y la preparación del encasillado.

${ }^{12}$ El Liberal (Sevilla), 6-4-1923.

${ }^{13}$ En el caso sevillano puede comprobarse una "transmisión de poderes" del Partido Liberal al Partido Conservador y un incremento de actividad en las que "se autotitulaban "verdaderas derechas"”. ÁlvAREZ REY, Leandro: Sevilla durante la dictadura de Primo de Rivera (la Unión Patriótica sevillana. 1923-1930). Diputación Provincial de Sevilla, 1987, págs. 37 y 64. 


\subsection{Realidades y proyectos de la Concentración Liberal}

El 18 de diciembre de 1922, el Gobernador civil de Huelva -Adolfo Ruiz Gutiérrez- cesaba en el desempeño de su cargo dando así cumplimiento al primero de una serie de cambios que el Gobierno presidido por García Prieto tenía destinados a la provincia. Su sustituto, el reformista José Eguizábal y Alonso de León, encajaba a la perfección en las necesidades del nuevo Gobierno: hombre respetado, famoso por la integridad y rectitud de su carácter, y sobre todo especialmente sumiso a las órdenes de la superioridad; era el «órgano de comunicación» y el «instrumento» ideal para un período como éste que se iniciaba con el anuncio de la convocatoria electoral. Su importancia estratégica se pondrá de relieve, de hecho, durante la dificultosa elaboración del encasillado onubense.

Como éste, los cambios siguientes tendrán también un marcado carácter electoral. Mientras que el nombramiento del romanonista Juan Moreno García como alcalde de Huelva parecía responder a razones eminentemente administrativas, es evidente que la sustitución de los alcaldes de La Palma y Ayamonte -encargada al jefe de los albistas onubenses - tenía el objeto de colocar en estas importantes cabeceras de partido judicial a hombres afectos al Gobierno que consiguiesen contrapesar la gran influencia de los conservadores en estas áreas. Aunque la prensa sevillana lanzaba al aire los nombres de los nuevos alcaldes en la tercera semana de febrero, la confirmación no llegó a Huelva hasta la primera semana de marzo. Los nuevos alcaldes -Francisco Castelló Arboleya, para La Palma, y José Cruz Romero, para Ayamonte-, extraídos de las filas albistas, despertaron desde el conocimiento de las pretensiones gubernamentales una intensa corriente de quejas en ambas localidades. El caso más agudo fue, no obstante, el de Ayamonte, donde, según recogía el diario onubense La Provincia, se recordaba «la última etapa liberal con disgusto" y se pensaba que suspendiendo al alcalde conservador se suspenderían también las reformas y mejoras que éste había prometido realizar. El mantenimiento de las críticas durante todo el mes de marzo retrasó los nombramientos y agudizó la corriente de opinión adversa a las realizaciones del Gobierno liberal. Para la prensa independiente todo formaba parte de los acostumbrados «chanchulleos, precursores de las elecciones», y esto le llevaba a comentar: 
«El amor a la patria no es compatible con el desbordamiento de intransigente voracidad electorera de los primates liberales que constituyen el Gobierno» ${ }^{14}$.

En efecto, así era. Como luego habría de exponer el órgano oficial del Partido Conservador, «la Concentración Liberal había suspendido una quincena antes de las elecciones a nada menos que 1.173 ayuntamientos" ${ }^{15}$. Con ello se deterioraba aún más la imagen pública del Gobierno garciprietista y se creaba un clima de opinión lo suficientemente impermeable a sus proyectos de reforma como para que éstos fueran duramente denostados. En este sentido - como ya hemos dicho con anterioridad-, no queda ahora dentro de nuestro interés establecer si hubo un verdadero intento de democratización y, en caso positivo, si éste hubiera sido fallido o no. Nos atendremos a una mera realidad, la desconfianza que la prensa independiente de Huelva demostró ante el programa reformista del Gobierno, y trataremos, solamente, de exponer ésta con la mayor brevedad y claridad posibles.

Si bien es cierto que la variedad interna de la Concentración Liberal nunca gustó demasiado a los redactores de La Provincia, cuando empezaron a sucederse las coyunturas críticas el disgusto pasó a ser un ataque frontal a todo lo que emanaba de la cúpula gubernamental. Romanones y Alcalá Zamora calificados como incompetentes y advenedizos en repetidas ocasiones; tampoco se ahorraron anatemas con García Prieto, que además de ser considerado como «la personificación de la mediocridad» fue definido como un hombre «incoloro, débil y asustadizo que no concibe la política sin la claudicación y el sometimiento". Si así se juzgaba a los artífices, podemos imaginar cómo serían juzgadas sus obras. El 4 de abril el editorial de La Provincia, bajo el título de «Un fracaso previsto", hablaba sin miramientos de la equívoca política reformista que había pensado "construir un nuevo edificio político con los cascotes del edificio ruinoso de la Restauración». En opinión del editorialista, ninguna reforma podría llegar a buen término si partía de un ejecutivo desintegrado internamente y falto de decisión debido a las fisuras de su composición. Por lo demás, conocido el programa electoral garciprietista, éste resultó a todas luces vago e insuficiente, incapaz por sí solo

${ }^{14}$ El Liberal (Sevilla), 27-2-1923; La Provincia, 6 y 14-3-1923, 1-6-1923. Durante la toma de posesión de Juan Moreno García, éste confesó su propósito de «hacer política, la política que todos conocen de procurar colocar a sus amigos con preferencia a los adversarios políticos". AMH, Acta Capitular de 1-6-1923, leg. 58.

15 TuselL, Javier, Oligarquía y caciquismo en Andalucia (1890-1923). Barcelona, Planeta, 1976, pág. 568 . 
de llevar a cabo esa efectiva y rotunda transformación del país por la que se clamaba incesantemente:

«Hoy como ayer, el Gobierno está en manos de los mismos hombres atenazados por los mismos compromisos, maniatados por idénticos convencionalismos e imposibilitados, por ello, de servir a los altos intereses de la patria'.

La declaración ministerial que acompañaba al decreto de disolución de las Cortes fue duramente criticada. La reforma del artículo 11, la conversión del Senado en una Cámara Corporativa y el resto de los cambios (ley electoral, Ejército, Hacienda, etc.) eran calificados como "altisonantes tópicos», con más voluntad de reforzar el encasillado que pretensión de realizarse. En definitiva, desde la perspectiva del diario onubense, la declaración toda no era sino un «documento fofo, inexpresivo, redactado con más reservas que sinceridades". Y se añadía: «sólo se ven los pingajos de la capa del liberalismo, hoja de parra tan reducida que apenas si sirve para ocultar sus vegüenzas y debilidades" ${ }^{16}$.

\section{LA ELABORACIÓN DEL ENCASILLADO. LA LUCHA PREELECTORAL Y EL PERFIL SOCIOPOLITICO DE LOS CANDIDATOS}

\subsection{Un encasillado problemático}

A principios de enero de 1923, comenzaron a aparecer en las páginas de la prensa de Huelva las primeras noticias sobre la preparación del encasillado electoral. Habida cuenta la excitación de la opinión pública ante el tema de las responsabilidades y los proyectos de reforma de la Concentración Liberal, el espectáculo que tal elaboración prometía se imaginaba verdaderamente curioso o interesante. Por lo pronto, podía constatarse en todos los ámbitos una reanimación de la vida política provincial, que salía así de su habitual letargo para cubrir una apretada agenda de viajes, conferencias y reuniones. Desde el principio, parecia evidente que los comicios de ese año serían más duros y disputados que los anteriores. En el caso onubense, el duque de Almodóvar - titular del

${ }^{16}$ Las críticas al programa reformistas gubernamental se pueden seguir en La Provincia (abril y mayo de 1923), de donde hemos sacado las citas. Sobre el contenido de dicho programa, vid. las obras citadas de Seco Serrano, Ben-Ami y Gonzalez Calbet. 
Ministerio de la Gobernación - no sólo debía afrontar las disputas entre las distintas facciones liberales lanzadas en toda España a una «guerra sin cuartel» ${ }^{17}$, sino que, además, debía enfrentarse a las desmedidas aspiraciones de un fuerte partido conservador acostumbrado a disfrutar desahogadas mayorías. Por otro lado, y como dificultad añadida, se imponía resolver con destreza la candidatura de un distrito problemático -el de Valverde del Camino- donde, desde 1914, podía hablarse de un grado considerable de modernización política ${ }^{18}$. Así las cosas, a nadie debió extrañar que el encasillado onubense fuese en extremo discutido y difícil de solventar. Finalmente -como siempre- el pacto sería alcanzado y respetado; sin embargo, es incuestionalbe que su consecución había supuesto la superación de numerosos obstáculos.

Tras la vuelta de Madrid del Gobernador civil, José Eguizábal, en la última semana de enero, empezó a rumorearse, desde el diario local $L a$ Provincia, una distribución del encasillado onubense que encajaba a la perfección en los repartos realizados en anteriores convocatorias. Cediendo el distrito de Aracena a los conservadores y asumiendo la representación liberal del de Valverde, el problema quedaba reducido al encasillado de la circunscripción que, desde su constitución en 1903, elegía tres diputados. Habitualmente, el partido gobernante se reservaba dos escaños y cedía uno al partido conservador. No obstante, con ocasión de la convocatoria de 1923, las cosas no parecían estar tan claras, puesto que, conocida la debilidad de los liberales en la provincia, se temía que los conservadores reclamasen una mayor participación ${ }^{19}$. A la espera de una información más exacta sobre las intenciones del Gobierno, los jefes provinciales de los partidos iniciaron una serie de contactos internos que ocuparon todo el mes de febrero. A lo largo de estos encuentros se revelaron ya como protagonistas fundamentales en la negociación Guillermo Moreno Calvo, Eguizábal y Burgos y Mazo. Al primero, jefe provincial de los albistas, correspondian de algún modo la representación de los intereses del Gobierno y el papel de catalizador de las diferencias entre las diversas facciones liberales. Sin embargo, su impopularidad entre el resto de los grupos políticos, a pesar de haber obtenido la representación parlamentaria durante tres legislaturas, hizo

17 González Calbet, M. T., Op. cit., pág. 105.

18 Tusell destaca como factores determinantes en este distrito la existencia de un poder económico independiente - las compañías mineras-y la importancia de las asociaciones sindicales. Prueba del comportamiento evolucionado de esta zona son las elecciones de 1918 y 1919, en las que Valverde elige al diputado republicano Eduardo Barriobero. TUSELL, J., Op. cit., págs. 249-252.

"La Provincia, 26-1-1923. 
que el gobernador civil, un hombre de reconocido prestigio, respetado por todos, se convirtiera en el verdadero moderador de la lucha por el encasillado, un resorte imprescindible para el Gobierno en el mecanismo político onubense. Por último, Burgos y Mazo, durante algunos años apartado de la política provincial activa, daba inconfundibles muestras de acrecentar su iniciativa, quizás con el único objeto de asegurar la candidatura oficial de su hijo, Manuel de Burgos Domínguez.

Los primeros contactos decisivos tuvieron lugar a mediados de febrero. La entrevista que mantuvieron Eguizábal, Limón Caballero y Burgos Domínguez ${ }^{20}$ se vio pronto secundada por una serie de reuniones mantenidas por Burgos y Mazo y el resto de los líderes políticos provinciales con motivo de una visita "política» de aquél a su íntimo amigo el senador Manuel Rebollo Orta, "una de las personalidades más relevantes del partido conservador " ${ }^{21}$. Ahora bien, será a primeros de marzo cuando el planteamiento del encasillado abandone la esfera provincial y se traslade a la capital para su resolución definitiva. Preocupado por no tener «aún decidido nada respecto a los términos generales en los que ha de resolverse la situación electoral en la mayoría de las provincias de España», el Gobierno debió pensar en una agilización de los trámites y convocó a los jefes onubenses. Con este motivo se desplazaron a Madrid el conservador Sánchez Dalp y Moreno Calvo, siendo muy probable que les acompañase también el romanonista Limón Caballero. Los resultados de las negociaciones en el Ministerio de la Gobernación tardaron aún algunos días en conocerse. Una vez roto el silencio, los primeros comentarios, filtrados desde el Congreso, sin ahorrar imprecisión y vaguedad, lanzaban al aire la posibilidad de una sorpresa "que ha de producir gran sensación en Huelva». En opinión del corresponsal, y como luego se hubo de confirmar, esta sorpresa no era sino la del encasillamiento de un liberal en el distrito de Aracena. $Y$ añadía:

«En el caso de que esto pudiera lograrse presentaría su candidatura por ahí un conocido escritor hijo de aquel distrito que goza en él de grandes simpatias. Al marqués de Aracena se le daria en compensación un acta de senador y acaso una senaduría vitalicia de las primeras que vacasen" ${ }^{22}$.

20 La Provincia, 15-2-1923.

21 Aguirre Lazareno, B., Op. cit., pág. 184. La Provincia, 16-2-1923 y El Liberal, Sevilla, 17-2-1923.

22 La Provincia, 1-3-1923. 
La noticia, evidentemente, habría de producir la prevista "sensación» en la política provincial. La designación de un candidato liberal en un distrito tradicionalmente conservador como el de Aracena, en el que la familia Sánchez Dalp ejercía un inveterado caciquismo, no sólo era una afrenta personal al marqués de Aracena sino también un insultante desafío para la organización conservadora de toda la provincia, que corría el riesgo de perder uno de sus baluartes más firmes y consolidados. En efecto, como ha analizado detenidamente Javier Tusell, el comportamiento electoral de este distrito serrano demuestra la existencia, desde 1903, de un predominio ininterrumpido del candidato Francisco Javier Sánchez Dalp, lo cual permite calificarlo como «distrito no competitivo" y modelo de lo que prototípicamente sería un "cacicato estable»" ${ }^{23}$.

Que la propuesta liberal desagradó profundamente a los conservadores es un hecho irrecusable. Como consecuencia inmediata de las ambiciones gubernamentales se establecerá en torno al encasillado onubense una dura pugna que no sólo retardará la resolución del pacto sino que, además, lesionará la estructura interna del partido conservador.

Ante las dificultades de la negociación, el día 7 de marzo el gobernador civil Eguizábal, que se encontraba recorriendo algunos pueblos de la provincia, fue llamado inesperadamente a Madrid por Almodóvar. La urgencia de este viaje despertó en Huelva comentarios de todo tipo. Los más acertados, sin duda, veían en la llamada al reformista un intento del Gobierno no reforzar sus bazas ante el pleito con los conservadores para conseguir finalmente imponerse. $Y$ añadian: devolviendo a la organización liberal onubense el "auge y vigor que siempre ha tenido" (! ${ }^{24}$. A pesar de todo, la destrucción de la tutela conservadora en la provincia necesitaba mucho más que la presencia de Eguizábal. En contrapartida, y como se desprende de una carta escrita por Sánchez Dalp a José Laguillo, director de El Liberal de Sevilla, los conservadores acudieron a la intervención de Burgos y Mazo para defender sus prerrogativas. El ex ministro supo resolver la situación satisfactoriamente, manteniendo incolumes las bases del conservadurismo onubense. Sin embargo, pronto la forzada intromisión del cacique moguereño pasó a convertirse en la manzana de la discordia entre éste y su sucesor en la jefatura provincial, que se había visto, así pues, relegado de sus más estrictas competencias. El enfriamiento de sus relaciones -encubierto siempre por un trato respetuoso y disimuladamentê cordial - se verá patentizado con la ausencia

23 TUSELL, J., Op. cit., págs. 227-231 y 236.

${ }^{24}$ El Liberal, Sevilla, 8-3-1923. 
del marqués en el banquete celebrado en honor de Burgos y Mazo el día 5 de abril y en posteriores actos conjuntos del partido ${ }^{25}$.

Solucionado lo referente al distrito de Aracena, y cuando todo parecía indicar que se podían abordar otros puntos neurálgicos de la candidatura oficial, un nuevo problema enturbió el desenlace del encasillado de Huelva. Se trataba, en este caso, de la dimisión de José Eguizábal. Empujado por la salida del ministro de Hacienda, el reformista Pedregal, $e$ incluso antes de que la noticia fuese oficialmente confirmada, el gobernador civil, haciendo gala de la «rectitud y entereza de su carácter», se apresuró a presentar su dimisión. Con ello, la Concentración Liberal se exponía a perder - poco más de un mes antes de las elecciones- una de las piezas claves de su intervención política en la provincia. Conscientes de que su gestión, que toda la prensa calfiicaba como «acertada», era imprescindible para el Gobierno, el duque de Almodóvar y Melquiades Álvarez enviaron sendos telegramas a Eguizábal indicándole "la conveniencia de que continuase en su puesto... donde tan buenos servicios presta» ${ }^{26}$. Eguizábal acató prudentemente las órdenes superiores, retiró su dimisión y las aguas volvieron a su cauce.

Contando con su anuencia, el encasillado podía proseguir. En principio el distrito de Valverde no presentaba más problema que el de concertar algunas alianzas de apoyo con las compañías mineras más importantes -especialmente con la de Río Tinto- y anular, mediante hábiles presiones, una posible candidatura de las fuerzas republicanas y socialistas que aquí contaban con gran arraigo ${ }^{27}$. Mayores quebraderos de cabeza ofrecía la candidatura oficial de la circunscripción, ya que Guillermo Moreno Calvo —que, junto a Burgos Domínguez y Limón, completaba la tríada original - presentaba el inconveniente de su impopularidad. Una impopularidad que, a medida que el encasillado se iba confirmando, se había convertido en verdadera enemistad. El corresponsal de La Unión de Sevilla traducía la situación con estas palabras:

«... el encasillado primitivo parece que no ha cuajado, ya que todos los elementos se han puesto frente al candidado y jefe de los albistas,

${ }^{25}$ La Provincia, 7-3-1923 y El Liberal, Sevilla, 8-3-1923 y 6-4-1923. Con anterioridad, la oferta de una senaduría vitalicia al Marqués de Aracena ya se había producido. El mismo Burgos y Mazo había escrito: «Hablé cor el marqués de Aracena proponiéndole concederle a él una senaduría vitalicia." Burgos y MAzo, Manuel, Memorias, t. XIV (Archivo de Burgos y Mazo), cit. en TuselL, Op. cit., pág. 284.

${ }^{26}$ La Provincia, 4 y 5-4-1923 y El Liberal, Sevilla, 5-4-1923.

27 Sobre la influencia de la Compañía de Río Tinto en los resultados electorales, vid. Tusell, J., Op. cit, pág. 203. 
señor Moreno Calvo, al que el señor Burgos y Mazo le ha declarado la guerra de exterminio..." "

Todas las fuerzas políticas de Huelva aparecían, así, coaligadas contra el jefe del albismo. Incluso José Tejero y González de Vizcaíno, un liberal independiente y "revolucionario incurable» que en las elecciones del 1920 "habían marchado de su brazo», la declaraba ahora una lucha frontal asegurando que él solo se bastaba "para aplastar al cacique de la Hericosa” ${ }^{28}$. Y realmente su amenaza debía ser temible, pues la influencia de Tejero, diputado en dos legislaturas y amigo íntimo del rey estaba fuera de toda duda en los círculos políticos onubenses.

En cualquier caso, desconocemos cuál fue la causa final que obligó al Gobierno a retirar la candidatura de Moreno Calvo. ¿Actuaron las presiones de los líderes onubenses $o$, por el contrario, las presiones capitalinas del nuevo candidato y sus amigos? Es muy probable que ambas razones se sumaran a la hora de transformar el encasillado. En definitiva, Moreno Calvo fue presentado por el distrito de Gaucín (Málaga), en el que finalmente obtendría el acta, y en su lugar se colocó la candidatura de un cunero: el albista Luis de Oteyza, director de El Liberal de Madrid ${ }^{29}$. Con ello, el encasillado llegaba a su fin y el cuadro completo de las candidaturas oficiales quedaba de la siguiente forma: por Aracena se presentaba - proclamado poco después por el artículo 29- el conservador Sánchez Dalp; por Valverde, el jefe provincial del partido reformista, Marchena Colombo; y por la circunscripción, Manuel de Burgos Domínguez, José Limón y Luis de Oteyza ${ }^{30}$.

No obstante, una cosa era el encasillado oficial y otra muy distinta las candidaturas no oficiales que pretendieran enfrentarse a él. Y si con el primero se ponía fin a la "lucha electoral" más efectiva de toda la convocatoria, con las segundas se ponían a prueba las escasas posiblidades de triunfo de las fuerzas situadas al margen del tunismo y su

${ }^{28}$ La Unión (Sevilla), 18-3-1923. AguirRe Lazareno, B., Op. cit., pág. 202.

${ }^{29}$ Diario de Huelva, 6-4-1923 y Correo de Andalucía (Sevilla), 7-4-1923.

${ }^{30}$ El encasillado oficial para la provincia de Huelva fue dado a conocer en la reunión del comité conservador onubense, recomendándose al electorado que votase la candidalura oficial. Como el mismo marqués de Aracena anunció, el acatamiento del pacto permitía que los conservadores designasen dos de los tres senadores que habían de ser elegidos con posterioridad y una mayoría de diputados provinciales. En opinión de la prensa local, el óptimo resultado obtenido por los conservadores se debía a que la Concentración Liberal no había tenido tiempo de eliminar sus estructuras de los distintos órganos administrativos de la provincia. La Provincia, 14 y 16-4-1923. 
capacidad para atraer a un electorado - el de las ciudades - que, en torno a 1923, daba ciertas señales de movilización política. En el caso onubense, serán las candidaturas en lucha por el distrito de Valverde del Camino y la disidencia del jefe local de los albistas, Nicolás Vázquez de la Corte, los elementos que realmente animen el panorama electoral con anterioridad al día de los comicios.

\subsection{Los atractivos de la convocatoria electoral}

El horizonte electoral comenzó a complicarse en el distrito de Valverde desde principios de abril con la presentación de las candidaturas de Manuel Fernández Balbuena y Diego Martínez Barrio. El primero, un ingeniero de minas, antiguo maurista muy vinculado a la zona de Andévalo, que contaba con el apoyo del algunas pequeñas compañías mineras y de la gran Compañía de Tharsis. El segundo, jefe de los republicanos lerrouxistas de Sevilla que, a pesar de no atravesar «un momento demasiado brillante" a la altura de $1923^{31}$, trataban de repetir la hazaña de Eduardo Barriobero en 1918 y 1919, contando con el apoyo de las organizaciones sindicales proletarias y la potencialidad del socialismo en la zona minera ${ }^{32}$. Como algunos comentaristas no tardaron en afirmar, la candidatura republicana por Valverde daba a la elección «caracteres épicos" y prometía una lucha "sañuda y vivísima", ya que "los republicanos poseen una poderosa organización en este distrito $y$, además, están dispuestos a echar el resto por el triunfo de su candidato"». Dispuestos, así, a restaurar glorias pasadas, los republicanos onubenses aprovecharon la candidatura de Martínez Barrio para organizar una intensa campaña electoral -la única de la que, con propiedad, puede hablarse en toda la convocatoria- en la que se prometía, incluso, la colaboración propagandística de Alejandro Lerroux ${ }^{33}$. En efecto, la cam-

31 Álvarez Rey, Leandro, Op. Cit., pág. 43.

${ }^{32}$ A este respecto, vid. Peña Guerrero, M. A.; Lara Rodenas, J. C. de y Dominguez, R., "La crisis de 1917 en Huelva». Huelva en su historia, 3. Huelva, Facultad de Ciencias Sociales y Jurídicas, (1989). GIL VARON, L., "Las luchas obreras en Río Tinto (1888-1920)", en Seis estudios sobre el proletario andaluz (1868-1939). Ayuntamiento de Córdoba, 1984.

${ }^{33}$ Hay que tener en cuenta que en la conciencia colectiva de los republicanos onubenses a pesar de su exacto conocimiento de las manipulaciones caciquiles, existía el convencimiento de que una buena campaña electoral podía llevarles al poder compensando las irregularidades de la maquinaria electoral. El triunfo de Barriobero en 1918 y 1919 (en este caso, tras la impugnación del pucherazo de Puebla de Guzmán) y la alta votación obtenida por Andrés Ovejero Bustamante en 1920 elevaron, sin duda, la moral republicana en abril de 1923. Diario de Huelva, 13-4-1923, La Unión (Sevilla), 18-4-1923 y El Liberal (Sevilla), 9-3-1923. 
paña electoral de Martínez Barrio, desde su llegada a Valverde el 13 de abril hasta su retirada una semana después - "en vista de las dificultades que a su entender hacían imposible el triunfo de la candidatura»-, nos ha dejado alguno de los episodios más representativos de una actuación política moderna, propia de los partidos democráticos de masas ${ }^{34}$. Jalonando su recorrido con numerosos actos de propaganda, el candidato republicano visitó los núcleos fundamentales de la cuenca minera -Zalamea, Nerva, Calañas y Valverde - pronunciando mítines multitudinarios como el de este último lugar, en que los amplios salones del Centro Republicano fueron insuficientes para contener a la «enorme concurrencia, teniendo que abrirse las ventanas para que el público escuchara desde la calle" ${ }^{35}$.

Con todo, antes de que el día 22 Martínez Barrio retirase su candidatura, un nuevo candidato había incrementado las expectativas de luchas en el distrito. Se trataba de Manuel del Pino González, catedrático del Instituo de San Isidro de Madrid y natural de El Cerro del Andévalo, que, en calidad de independiente, buscaba el acta valverdeña valiéndose de las «muchas simpatías" que allí gozaba. Tan sólo cuatro días duró la fugaz campaña de Pino; lo suficiente para calibrar el balance de fuerzas existentes en su "amadísimo distrito» y comprender que poco podía hacer frente a las cartas jugadas por Marchena Colombo, al que apoyaban conservadores, limonistas, albistas y la poderosa Compañia de Río Tinto. Así pues, cinco días antes de la jornada electoral, la lucha había quedado reducida a las candidaturas de Marchena y Fernández Balbuena ${ }^{36}$.

En cuanto a la circunscripción, la animación de la campaña electoral vino dada por la candidatura disidente del ex-alcalde de la ciudad y jefe local de los albistas, Nicolás Vázquez de la Corte ${ }^{37}$. Rebelde a las disposiciones de un encasillado oficial en el que él, desde un principio, había fijado sus aspiraciones, y consciente de que sólo contaba con sus propias fuerzas, el entonces concejal del Ayuntamiento presentó su candidatura despreciando todo tipo de oposiciones. Bien poco lograron, en este sentido, las entrevistas con su jefe provincial o con el mismo Santiago Alba. Tampoco sirvieron para nada las presiones ejercidas por Luis de Oteyza, que consideró esta actitud de Vázquez de la Corte como "un

34 Vid. Gónzalez Calbet, M. T., Op. cit, págs. 100 y s.

${ }^{35}$ La Provincia, 21-4-1923 y El Liberal (Sevilla), 22-4-1923.

${ }^{36}$ El Liberal (Sevilla), 20-4-1923 y La Provincia, 24-4-1923.

${ }^{37}$ "Es muy frecuente el caso de que quienes luchan en contra de los candidatos encasillados por el Gobierno no sean miembros del partido del turno que está en la oposición sino por el contrario, del que está en el poder». TuseLL, J., Op. cit., pág. 126. 
agravio personal» y le dirigió un airado telegrama de protesta. En algún sentido, todas estas coacciones eran lógicas. La candidatura disidente impedía la aplicación del artículo 29 y, además, exponía al Gobierno al riesgo de una victoria en la capital que habría que compensar con procedimientos fraudulentos. Una candidatura, por tanto, doblemente peligrosa y molesta que, para mayor inquietud, contaba con precedentes como el de 1920, cuando para anular la victoria en Huelva de un monárquico no encasillado hubo que recurrir al pucherazo ${ }^{38}$.

Así pues, agitados por los resultados de la circunscripción y por la intensidad de la campaña en Valverde, los dias previos a la jornada del 29 de abril transcurrieron en un clima de tensión y excitación que, a pesar de su atractivo para la opinión pública, no redundaron en honradez y autenticidad del proceso electoral ${ }^{39}$.

\section{LOS RESULTADOS ELECTORALES: BALANCE CUANTITATIVO $Y$ CUALITATIVO}

\subsection{El desarrollo de las elecciones. Los resultados}

La jornada electoral del 29 de abril transcurrió en la provincia de Huelva con tanta serenidad como desánimo. Eliminada la confrontación en el distrito de Aracena mediante la aplicación del artículo 29, la circunscripción y el distrito de Valverde presentaban una situación tan claramente favorable a las candidaturas oficiales que no se hizo necesario el recurso a procedimientos en extremo fraudulentos como la compra de votos, la coacción o la suplantación de votantes. No obstante, en opinión de Nicolás Vázquez de la Corte y Manuel Fernández Balbuena, candidatos no encasillados, el desarrollo de la elección no había sido tan fácil y limpio como los medios oficiales se empeñaban en asegurar.

En Valverde, los partidarios de Balbuena consignaron las protestas de sus interventores por la expulsión de los notarios en algunos colegios

${ }^{38}$ La Unión (Sevilla), 12-4-1923, El Liberal (Sevilla), 20 y 28-4-1923, La Provincia, 13 y 23-4-1923. TUSELL, J., Op. cit., pág. 151.

${ }^{39}$ Sobre la autenticidad del proceso electoral en España, vid. las obras citadas en la nota 1 y Álvarez ReY, L., Op. cit., para el caso concreto de Sevilla. Sobre el desarrollo en Andalucía, vid. TUSELL, J., Op. cit. 
electorales ${ }^{40}$. En la circunscripción, los electores de Vázquez de la Corte testimoniaron ciertos casos que demostraban un claro pucherazo de las mesas rurales para dar la victoria al cunero Luis de Oteyza, que, a tenor de los votos, había sido derrotado en la capital. La victoria del albista disidente fue interpretada en todos los sectores de opinión como una manifestación más del malestar que despertaba en la ciudadanía la imposición, por parte del Gobierno, de un candidato cunero desconocido y ajeno a la vida política provincial. La Provincia juzgaba la situación en estos términos:

«En todos los distritos excepto en el de San Pedro, que dirigen los amigos Garrido Perelló y Vázquez del Cid, el candidato protestante obtuvo una lucida mayoría, obteniendo su candidatura más de 1.000 votos sobre la oficial. Numerosos electores de filiación política distinta al batallador concejal le votaron sin vacilaciones ni dudas. Lo mismo los de las derechas que los republicanos quisieron ayer evidenciar su protesta contra la imposición del Gobierno, y lo hicieron con una elocuencia digna de que los directores de la política local mediten sobre ella (...). Claro está que luego llegaron los pueblos que votan con la circunscripción para dar la razón al Gobierno, pero eso, nada significa ni representa porque, lo repetimos: la protesta quedó evidenciada, manifestándose la opinión onubense en contra del Gobierno» ${ }^{41}$.

Es evidente que las elecciones de 1923 ponían de relieve la existencia en Huelva - como en tantas otras ciudades- de «un electorado políticamente movilizado que hacía imposible la manipulación electoral» ${ }^{42}$ y que, sin embargo, a diferencia de lo ocurrido en grandes núcleos como Madrid o Barcelona, seguía siendo incapaz de controlar las maniobras fraudulentas en el área rural.

Los resultados electorales de la circunscripción, que recogemos en el siguiente cuadro, demuestran fehacientemente el pucherazo gubernamental contra la candidatura de Vázquez de la Corte:

${ }^{40}$ TUSELL, J., Op. cit., pág. 252.

${ }^{41}$ La Provincia, 30-4-1923.

42 González Calbet, M. T., Op. cit., pág. 110. 


\begin{tabular}{|c|c|c|c|}
\hline \multirow{2}{*}{ Candidatos } & \multicolumn{3}{|c|}{ Número de votos } \\
\hline & Capital & Resto circunsc. & Total \\
\hline Vázquez de la Corte ........ & 2.107 & 5.262 & 7.369 \\
\hline Oteyza $\ldots \ldots \ldots \ldots \ldots \ldots$ & 852 & 10.895 & 11.747 \\
\hline Burgos Domínguez ......... & 1.787 & 19.998 & 21.785 \\
\hline Limón Caballero ............. & 1.496 & 13.397 & 14.893 \\
\hline
\end{tabular}

Fuente: La Provincia, 30-4-1923 y 3-5-1923, y Acta de la Junta Provincial del Censo Electoral, 3-5-1923, Archivo de la Diputación Provincial de Huelva, libro 328. Elaboración propia.

Las cifras registradas nos permiten comprobar que Vázquez de la Corte no sólo fue más votado que Oteyza en cinco de los seis distritos de la capital sino que, además, fue el candidato más votado, superando con creces a la candidatura oficial en cuatro de estos distritos. Lejos de reflejar esta misma tendencia, el recuento de los votos en el entorno rural provocó una inversión clara de los resultados que, en ocasiones, presentaron evidentes señales de manipulación. Así, por ejemplo, en Hinojos, Isla Cristina o Palos, la candidatura del jefe albista onubense no alcanzó ni un solo voto. Poco más tarde, el alto tribunal afirmaba que "no deja de ser extraño que no se asignara el reclamante ( $y$ candidato de la oposición) voto alguno». Sin embargo, también es cierto, como ha señalado Javier Tusell, que el hecho de que «la lectura de las actas indujera a la sospecha no quería decir, desde luego, que con ello quedara probada» ${ }^{43}$.

Con motivo de la proclamación de los diputados en la reunión de la Junta Provincial del Censo Electoral, Vázquez de la Corte enumeró una tras otra las írregularidades cometidas en algunas localidades. Aparte mencionar los casos en que ni siquiera fueron abiertos los colegios electorales o en que las certificaciones presentaban una fecha errónea, se detuvo extensamente en los casos de Bonares y Cartaya, donde su candidatura sólo habia obtenido 29 sospechosos votos. Aseguró que «un señor en Huelva tenía el domingo en los bolsillos los documentos pertenecientes al pueblo de Bonares», y, respecto a Cartaya, expuso cómo la urna había sido abandonada por los integrantes de la mesa, siendo ne-

${ }^{43}$ Diario de Sesiones del Congreso, 5-6-1923, apéndice 1. TuSELL, J., Op. cit., pág. 154. 
cesario que la Guardia Civil se encargase de llevarla al Juzgado municipal. Finalmente, las protestas se saldaron con la refutación de Limón Caballero y un oficio de Santiago Hueto, presidente de la mesa electoral de Cartaya, a la Junta del Censo, donde se justificaba la entrega de la urna a la Guardia civil por haber recibido violentos ataques de un elector ${ }^{44}$.

En cualquier caso, reconocida o no la protesta, tanto la prensa onubense como la sevillana coincidieron en considerar que la única votación representativa de la voluntad popular había sido la de la ciudad de Huelva y ello, indudablemente, sólo podía tener una lectura: la absoluta pérdida de credibilidad del sistema canovista. Que las elecciones venían a ser el remate de una agonía progresiva del poder, acelerada desde 1917 y consumada definitivamente con el Gobierno de la Concentración Liberal, era incuestionable. Y si -como hemos tenido ocasión de comprobar- nunca existió una verdadera confianza en el programa reformista de García Prieto, el alarde manipulador del Ministerio de la Gobernación en abril de 1923 acabó por escindir de forma tajante los intereses nacionales de los intereses de un electorado -el onubenseque parecía haber alcanzado ya su madurez política. Por lo demás, para el Gobierno, la lectura debía ser igualmente elocuente. $\mathrm{Si}$, como habría de indicar Gabriel Maura algo más tarde, existía "una más exacta apreciación de la vida española" de tal manera que no se podía "confundir la mayoría parlamentaria con la nacional» ${ }^{45}$, el Gobierno debió entender claramente que los resultados electorales no le demostraban el debido apoyo popular ni le garantizaban un respaldo social sólido para sus pretensiones reformistas. Después de la cesión a los conservadores del distrito de Aracena, la victoria urbana de uno de sus miembros rebeldes asestaba un segundo y potente golpe al deseo de los liberales onubenses de asentar su poder en la provincia sobre bases consistentes, fueran éstas espontáneas o artificiales.

Ahora bien, no sólo los liberales sintieron la conmoción de los resultados. En los días que sucedieron al domingo electoral, la primera de las fuerzas políticas de la provincia - el partido conservador- debió realizar un balance de la situación lo suficientemente negativo como para que incluso en Diario de Huelva, propiedad de la familia de Mora Claros, se juzgasen los resultados como una derrota «bochornosa y total» para los

44 La Provincia, 3-5-1923. Archivo de la Diputación Provincial de Huelva (ADPH), Actas de la Junta Provincial del Censo Electoral, libro 328.

${ }^{45}$ Maura, Gabriel, Bosquejo histórico de la Dictadura, Madrid, 1930, pág. 9. Cit. en Ben-Ami, Sh., Op. cit., págs. 26 y s. 
conservadores onubenses. Haciéndose eco de la «marejada política» existente en este grupo, El Liberal sevillano daba cuenta de la intención de Burgos y Mazo de reorganizar la estructura provincial del partido, comenzando por solventar la difícil designación de un nuevo jefe local ${ }^{46}$. Es muy posible que, en efecto, la ausencia de un hombre fuerte como Mora Claros hubiese debilitado la influencia del partido a la hora de determinar el voto en la capital. No obstante, es obvio que el clima de oposición que, desde la prensa, había acompañado todo el proceso electoral fue también un factor decisivo a la hora de desviar al electorado del encasillado oficial.

\subsection{Las críticas al proceso electoral}

El matiz novedoso que las elecciones de 1923 pudiesen tener, por la implicación en ellas de la cuestión de las responsabilidades por el desastre de Marruecos y las reformas anunciadas por el Gobierno, quedó pronto anulado en cuanto comenzaron a conocerse las componendas del encasillado y el retorno a los vicios habituales del sistema ${ }^{47}$. En Huelva, fue la imposición del candidato madrileño, Luis de Oteyza, lo que centró el núcleo de las protestas. En una carta del reformista Pedro Seras a Modesto Pineda, director de La Provincia, este hecho era considerado como una afrenda a Burgos y Mazo, que había conseguido librar la política onubense del cunerismo «tan vergonzosamente arraigado antes». Acto seguido, se animaba al electorado a combatir con su voto el maltrato usado por el Gobierno, demostrando la adhesión a los candidatos coprovincianos ${ }^{48}$. Comentarios similares frecuentaron las crónicas periodísticas antes y después de la jornada electoral. El deshonroso «estigma» del cunerismo, no obstante, suscitó los comentarios más agrios una vez conocida la victoria de Vázquez de la Corte frente a Oteyza en las mesas de la capital. Así, haciendo causa común con lo sucedido en Sevilla entre Martínez Barrio y el cunero Luca de Tena, La Provincia dedicó un amplio editorial a criticar lo sucedido:

«El cunerismo, que en los distritos rurales es una sangrienta burla, un escarnio afrentoso contra la conciencia ciudadana, en las capitales es algo más todavía: es el salibazo depresivo que se arroja a la cara de los ciudadanos declarándoles imbéciles e incapaces de discernir sobre aquello que más les afecta en sus intereses (...) Que el candidato

\footnotetext{
46 El Liberal (Sevilla), 3-5-1923.

47 Tusell, J., Op. cit., págs. 565 y s.

${ }^{48}$ La Provincia, 6-4-1923.
} 
disidente don Nicolás Vázquez de la Corte, sin organizaciones propias, sin elementos que le apoyaran, desautorizado por el mismo partido en que milita, casi sin intervención ni quienes defendieran su candidatura, haya obtenido una gran mayoría en la capital, es algo elocuentísimo y plausible que demuestra que no en balde se reta a todo un pueblo pretendiendo sojuzgarlo y anular su voluntad" 49 .

Las críticas de este y otros artículos semejantes iban dirigidas directamente hacia el Gobierno; en ocasiones, la figura del cunero se defendía, incluso, como víctima de un sistema injusto e irracional. Todo servía, en definitiva, para sacar al electorado de su equívoca confianza en la representación parlamentaria:

«Los inocentes que aún tenían alguna fe en eso del sufragio, deben enterarse bien de que no hay medio posible de elegir diputados que no sean gratos a los que mangonean en la cosa pública, llámense conservadores o liberales» ${ }^{50}$.

Conservadores y liberales se veían, así pues, salpicados por las lacras del cunerismo, mientras que las protestas continuaban, o mejor, se avivaban con motivo de la elección de senadores, en la que Huelva habría de recibir un nuevo cunero - habitual, por lo demás-: el garciprietista marqués viudo de Mondéjar. Votado religiosamente por los compromisarios dentro de la tríada que - bajo auspicios conservadorescompletaban José Valero Hervás y José María Jiménez Molina, poco más que el nombre sabían los onubenses sobre este senador impuesto desde Madrid y que, una vez desatadas las críticas contra el cunerismo, recibiría curiosos apelativos como «fantasma sin existencia real» o «enigmático espíritu, ... tan ajeno a nosotros como un habitante de la luna».

Pero si duros habían sido los ataques al cunerismo, no menos fuertes fueron las críticas dirigidas al "cómodo y económico artículo 29» que, desde el 22 de abril — día de la presentación de candidaturas-, había supuesto la automática proclamación de Sánchez Dalp por el distrito de Aracena. Ahora bien, en este caso, las protestas no fueron dirigidas a la aplicación del artículo en la provincia, sino al uso alarmante que se había hecho de él en toda la nación, redundando esto en «desprecio y mengua

${ }^{49}$ La Provincia, 2-5-1923. Editorial «Las enseñanzas de unas elecciones».

${ }^{50}$ La Provincia, 5-5-1923. Editorial "Verdades como puños". 
del elector" ${ }^{51}$. No es de extrañar esta postura si tenemos en cuenta que, en el distrito de Aracena, éste había sido el sistema de proclamación más normal desde 1907 hasta 1916 y que el marqués de Aracena había sido en todas estas ocasiones y en los comicios de 1918, 1919 y 1920, el candidato victorioso ${ }^{52}$. Podemos entender, así, que por razón de costumbre los onubenses no protestaran de su situación sino de la del resto del país, ya que los 146 diputados designados sin lucha ni voto venían a agravar, de algún modo, el clima de corrupción que rodeaba todo el proceso electoral. Su proclamación ponía fin a la elaboración del encasillado y a la única lucha que realmente se puede reseñar en todas las elecciones de la Restauración: la lucha pre-electoral ${ }^{53}$.

En los días inmediatamente anteriores a la elección, a nadie se ocultaba ya que el Gobierno de García Prieto se había empleado a fondo en la elaboración de su propia victoria. La proclamación del día 22 sólo había sido, en este sentido, la primera recogida de una cosecha cuyos frutos finales, por lo general anticipadamente conocidos, merecerían el siguiente comentario editorial de La Provincia:

«... el país sabrá a esa hora ciertamente lo que viene sospechando desde que se anunciaron las elecciones, sin que pueda sorprenderle nada de lo que salga de las urnas por tenerlo descontado, que ahora como antes, cohartado (sic) el derecho de ciudadanía por medios reprobables, la voluntad de los españoles no se pondrá mañana de manifiesto a pesar de las mentirosas promesas de los gobernantes, tan puritanos cuando hablan al país desde la oposición y tan chanchulleros cuando preparan en el Ministerio de la Gobernación el Parlamento que necesitan para continuar detentando el Poder» ${ }^{54}$.

\subsection{Balance final}

Si en algún momento los liberales habían confiado en su programa de reformas para convertirse en los regeneradores del país, está bien

51 La Provincia, 24-4-1923.

52 Martínez Cuadrado, M., Elecciones y partidos políticos en España. Madrid, Taurus, 1969, apéndice estadístico. De hecho, el artículo 29 no había afectado nunca a otro candidato, excepto en el caso de las elecciones de 1916, en que los cinco diputados de la provincia fueron designados por este sistema.

${ }_{53}$ En este sentido ha escrito Tusell: "Las elecciones (de 1923) han sido en algún sentido competidas, pero sólo en el período inmediatamente anterior a la proclamación de las candidaturas." TUSELL, J., op. cit., pág. 570.

${ }^{54}$ La Provincia, 28-4-1923. Editorial «iNo va más! Lo mismo de siempre». 
claro que, una vez conocida la constitución de las nuevas Cortes, este papel les seria negado desde la mayor parte de los sectores políticos. Como indica Tusell, superada la jornada electoral, "la sensación de estabilidad del caciquismo es, sin duda, la predominante» y el significativo voto de las ciudades - a pesar de señalar «un cambio de rumbo trascendental»- se ve anulado por la sensación de inmutabilidad de la vieja política ${ }^{55}$. Estas afirmaciones se ajustan perfectamente al caso onubense. El saldo arrojado por la convocatoria electoral de 1923 refleja un claro mantenimiento de la estructura de poder existente en la provincia. La reconstrucción, en líneas generales, de los resultados de convocatorias anteriores, nos permite contemplar, desde una perspectiva más amplia, el significado de los comicios de 1923 en Huelva.

\begin{tabular}{|c|c|c|c|c|c|}
\hline \multirow{2}{*}{ Años - } & \multicolumn{4}{|c|}{ Número de escaños obtenidos } & \multirow{2}{*}{$\begin{array}{c}\text { Gobierno } \\
\text { organizador }\end{array}$} \\
\hline & Liberales & Conservad. & Republic. & Reformist. & \\
\hline 1910 & 3 & 2 & - & 一 & Liberal \\
\hline 1914 & 2 & 3 & - & - & Conservador \\
\hline 1916 & 2 & 3 & - & - & Liberal \\
\hline 1918 & 1 & 3 & 1 & - & Liberal \\
\hline 1919 & 1 & 3 & 1 & - & Conservador \\
\hline 1920 & 1 & 4 & - & 一 & Conservador \\
\hline 1923 & 2 & 2 & - & 1 & Liberal \\
\hline
\end{tabular}

Fuente: Junta Provincial del Censo Electoral (Archivo de la Diputación Provincial de Huelva, libros 324 y 326 a 328). Martínez CuAdrado, M., Elecciones y partidos políticos en España. Madrid, Taurus, 1969, apéndice estadístico. Elaboración propia.

El predominio conservador se refleja en el cuadro anterior como una constante, al menos, desde 1910. Incluso en comicios organizados por el partido liberal, los conservadores onubenses nunca bajaron de dos diputados; es más, en algunas ocasiones, 1916 y 1918 por ejemplo, llegaron a ser mayoría con gobiernos liberales. Por lo general, su participación en el encasillado fue siempre altamente favorable. Así pues, en 1923, per-

\footnotetext{
${ }^{55}$ Tusell, J., Op. cit., pág. 573.
} 
siste plenamente el bastión conservador de la provincia en torno al cacicato de Burgos y Mazo, ya que - a pesar de las diferencias internas, las críticas y la vacancia de la jefatura local de Huelva - basa su hegemonía en la debilidad de los liberales y la inexistencia de otra alternativa partidista. El encasillado de 1923 ha puesto de relieve, una vez más, las dificultades del grupo liberal para imponerse a las prerrogativas de los conservadores onubenses. Esto no sólo se ha hecho presente en la defensa del distrito de Aracena - considerado casi como una propiedad del partido inalienable - sino también durante el resto de las elecciones de este año - las del Senado y la Diputación Provincial-, en las que los conservadores han demostrado una potestad absoluta ${ }^{56}$. Por lo demás, una tercera fuerza, el partido reformista, con cierto predicamento en la provincia, ha colocado un diputado en el distrito de Valverde. La elección de José Marchena Colombo, resultado de una votación «sorprendente" ${ }^{57}$, demostraba la vitalidad del partido en los últimos años, y algunos sectores de inclinación demócrata comenzaron a abrigar la esperanza de que la política onubense empezase a discurrir por los cauces del reformismo. Sin embargo, el descrédito del reformismo a nivel nacional por su asociación con García Prieto poco podía beneficiar a un núcleo marginal como el de Huelva que, pese a sus éxitos, carecía aún de verdadero arraigo.

Como balance final, un tanto apresurado y comprimido por la brevedad de esta comunicación, las conclusiones que anteceden bien pueden valer para ofrecer una idea clara sobre el estado en que se encontraba la estructura política de Huelva ante el advenimiento de la Dictadura de Primo de Rivera. No redundaremos, por ello, en exponer nuevamente afirmaciones que, a lo largo de estas páginas, hemos tratado de dar a conocer con la mayor claridad posible. Sin embargo, no quisiéramos acabar este análisis sobre los comportamientos de la élite política onubense durante las elecciones de 1923 sin mencionar algunos aspectos que consideramos de gran importancia pero que, lamentablemente, no hemos podido abordar. Por una parte, es necesario proceder a un estudio más profundo de los verdaderos poderes fácticos que movían el engranaje político onubense y que, a veces, desde la sombra, podían tener en su mano el resultado de la iucha electoral. Figuras como las de Manuel Rebollo Orta, Antonio de Mora Claros, o la misma Compañía de Río

${ }^{56}$ Dos de los tres senadores y cinco de los ocho diputados provinciales elegidos por La Palma y Valverde fueron conservadores. El resto de los datos no se dieron a conocer oficialmente. La Provincia, 14-5-1923 y 11-6-1923.

57 El Liberal, Sevilla, 3-5-1923. 
Tinto, deben, en este sentido, ser investigadas con mayor detenimiento. Por otro lado, conscientes de que a nosotros sólo llega a veces una información restringida de las verdaderas maniobras políticas emprendidas por los distintos grupos, se impone efectuar un trabajo más completo de localización y análisis de los fondos documentales privados pertenecientes a políticos de Huelva. Un trabajo, sin duda, más laborioso y lento que, desde este momento, nos comprometemos a abordar. 